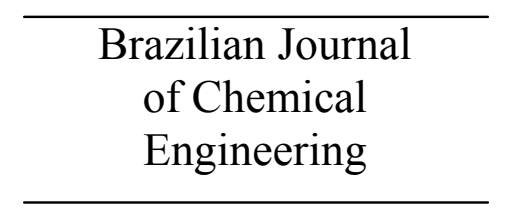

ISSN 0104-6632

Printed in Brazil

www.abeq.org.br/bjche

Vol. 25, No. 04, pp. $799-812$, October - December, 2008

\title{
OPTIMAL CONTROL OF A CSTR PROCESS
}

\author{
A. Soukkou ${ }^{*}$, A. Khellaf ${ }^{2}$, S. Leulmi ${ }^{3}$ and K. Boudeghdegh ${ }^{4}$ \\ ${ }^{1}$ Department of Electronics, University of Jijel, BP. 98, Ouled Aissa, Jijel 18000, Algeria. \\ E-mail: soukkou_a@yahoo.fr
${ }^{2}$ Department of Electronics, University of Ferhat Abbas-Setif 19000, Algeria. \\ E-mail: ah_khellaf@yahoo.fr \\ ${ }^{3}$ Department of Electrotechnics, University of Skikda 21000, Algeria. \\ E-mail: leulmi_salah@yahoo.fr \\ ${ }^{4}$ Department of Chemical Engineering, University of Jijel, BP. 98, \\ Ouled Aissa, Jijel 18000, Algeria. \\ E-mail:kameltan@yahoo.com
}

(Received: March 12, 2007 ; Accepted: April 24, 2008)

\begin{abstract}
Designing an effective criterion and learning algorithm for find the best structure is a major problem in the control design process. In this paper, the fuzzy optimal control methodology is applied to the design of the feedback loops of an Exothermic Continuous Stirred Tank Reactor system. The objective of design process is to find an optimal structure/gains of the Robust and Optimal Takagi Sugeno Fuzzy Controller (ROFLC). The control signal thus obtained will minimize a performance index, which is a function of the tracking/regulating errors, the quantity of the energy of the control signal applied to the system, and the number of fuzzy rules. The genetic learning is proposed for constructing the ROFLC. The chromosome genes are arranged into two parts, the binary-coded part contains the control genes and the real-coded part contains the genes parameters representing the fuzzy knowledge base. The effectiveness of this chromosome formulation enables the fuzzy sets and rules to be optimally reduced. The performances of the ROFLC are compared to these found by the traditional PD controller with Genetic Optimization (PD_GO). Simulations demonstrate that the proposed ROFLC and PD_GO has successfully met the design specifications.

Keywords: Intelligent control; Genetic learning; PPDC; Reduced rule base.
\end{abstract}

\section{INTRODUCTION}

Recently, with the increasing research activities in the field of structural control, many control methods have been proposed and implemented. These methods are fuzzy control, optimal control, pole placement, sliding mode control, etc. (ChengWu Chen, 2006).

Fuzzy logic has emerged as an alternative approach introduced firstly by L. A. Zadeh in 1965 in a publication called "Fuzzy Sets" (Zadeh, 1965). A fuzzy system is a system based on the concepts of approximate reasoning for representing uncertain and imprecise knowledge. There are two fuzzy modelling approaches depending on the main objective to be considered (Casillas et al., 2005):

- linguistic fuzzy modelling mainly developed by linguistic fuzzy rule-based systems (Mamdani, 1974) (or Mamdani- type fuzzy reasoning);
- precise fuzzy modelling, mainly developed by Takagi-Sugeno fuzzy rule-based systems (Takagi and Sugeno, 1985).

In the fuzzy modelling, the structure identification/learning task consists of making the following choices:

1) Model type;

2) Model size;

3) Number of linguistic values defined for each input/output variable.

The main steps in the design of a fuzzy model include building control rules, establishing the rule base, stating the Membership Functions (MFs) and tuning the scaling factors (Chih-Hsun Chou, 2006). To design an optimal controller, an efficient optimization technique should be used. In particular, Evolutionary computation has received considerable attention in recent years (Kwee-Bo Sim et al., 2004). Genetic Algorithms (GA) (Goldberg, 1994) have

*To whom correspondence should be addressed 
been proposed as a learning method that allows automatic generation of optimal parameters for fuzzy controllers based on an objective criterion.

Concerning the performance of fuzzy control systems, the optimality and robustness have quite often been considered as the important issues. Specifically, on the optimality issue for fuzzy control systems (Yonmook Park et al., 2004).

A good optimal control technique, especially when applied for the first time on a particular process, should (Upreti, 2004):

1) provide consistent, good quality results regardless of starting points;

2) use a reasonable amount of performance index evaluation.

The design problem considered in this paper is essentially a nonlinear optimal and robust control problem due to the nonlinear nature of the TakagiSugeno fuzzy system. In order to obtain the latter, which can provide the minimized control effort, we formulate the controller design problem as the Proportional Parallel Distribution Compensation (PPDC) problem (Er et al., 2002), and find the controller by the genetic learning algorithm. The objective is to obtain the optimal control function, which would optimize a desired performance index.

The remaining part of this paper is organized as follows. The design and learning algorithm of the proposed system is described in the next two sections. Then, some simulation results to illustrate the effectiveness of the proposed control system structure are displayed. Finally, conclusions are presented in the last section.

\section{CONTROL DESIGN}

\section{CSTR Process Description}

In this paper, we consider the control problem of a class of Continuously Stirred Tank Reactor (CSTR) systems (Figure 1) given in (Oysal et al., 2003; Oysal et al., 2006; Aoyama et al., 1995; Zhang, Guay, 2005). The process dynamics are described by (Chia-Feng Juang, 2007)

$$
\begin{aligned}
& \dot{\mathrm{x}}_{1}(\mathrm{t})=\mathrm{f}_{1}\left(\mathrm{x}_{1}(\mathrm{t}), \mathrm{x}_{2}(\mathrm{t})\right)+\left(\frac{1}{\sigma}-1\right) \mathrm{x}_{1}(\mathrm{t}-\tau) \\
& \dot{\mathrm{x}}_{2}(\mathrm{t})=\mathrm{f}_{2}\left(\mathrm{x}_{1}(\mathrm{t}), \mathrm{x}_{2}(\mathrm{t})\right)+ \\
& \left(\frac{1}{\sigma}-1\right) \mathrm{x}_{2}(\mathrm{t}-\tau)+\beta \cdot \mathrm{u}(\mathrm{t})+d_{\text {ist }}(\mathrm{t})
\end{aligned}
$$

where $\sigma, \tau$ and $\beta$ are constants. The component $\mathrm{x}_{1}(\mathrm{t})$ is the conversion rate of the reaction component $\mathrm{A}, 0<\mathrm{x}_{1}(\mathrm{t})<1, \mathrm{u}(\mathrm{t})$ is a dimensionless coolant temperature $\mathrm{x}_{2}(\mathrm{t})$ is the dimensionless temperature and $f_{1}$ and $f_{2}$ are given by

$$
\begin{aligned}
& \mathrm{f}_{1}\left(\mathrm{x}_{1}(\mathrm{t}), \mathrm{x}_{2}(\mathrm{t})\right)=-\frac{1}{\sigma} \mathrm{x}_{1}(\mathrm{t})+ \\
& \mathrm{D}_{\mathrm{a}}\left(1-\mathrm{x}_{1}(\mathrm{t})\right) \exp \left(\frac{\mathrm{x}_{2}(\mathrm{t})}{1+\mathrm{x}_{2}(\mathrm{t}) / \gamma}\right) \\
& \mathrm{f}_{2}\left(\mathrm{x}_{1}(\mathrm{t}), \mathrm{x}_{2}(\mathrm{t})\right)=-\left(\frac{1}{\sigma}+\beta\right) \mathrm{x}_{2}(\mathrm{t})+ \\
& \operatorname{HD}_{\mathrm{a}}\left(1-\mathrm{x}_{1}(\mathrm{t})\right) \exp \left(\frac{\mathrm{x}_{2}(\mathrm{t})}{1+\mathrm{x}_{2}(\mathrm{t}) / \gamma}\right)
\end{aligned}
$$

The constant parameters are given as:

$\sigma=0.8 \quad \beta=0.3 \quad \mathrm{D}=0.072 \quad \mathrm{H}=8 \quad \tau=2 \quad \gamma=20$

The parameters of the plant are defined in Table 1 (K. Belarbi et al., 2005). It is assumed that the external disturbances (see Figure $2(b)) d_{\text {ist_1 }_{1}}(t)$ and $\mathrm{d}_{\text {ist_2 }}(\mathrm{t})$ are given by the Van der Pol equations and depicted by Figure 2 (a).

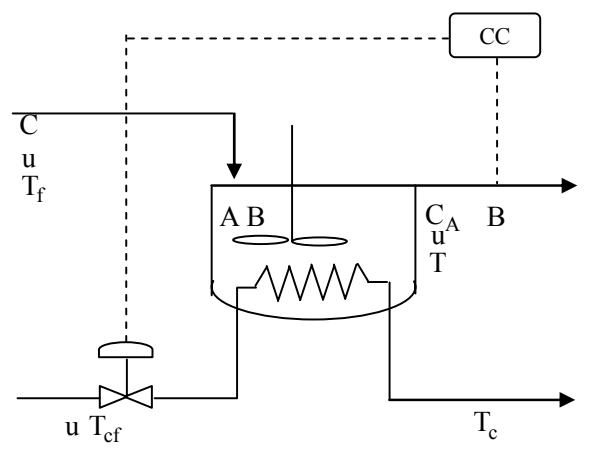

Figure 1: Continuous Stirred Tank Reactor. 
Table 1: CSTR parameters

\begin{tabular}{|l|l|}
\hline Parameter & Description \\
\hline $\mathrm{C}_{\mathrm{A}}(\mathrm{t})$ & Chemical concentration of component $\mathrm{A}$ \\
$\mathrm{C}_{\mathrm{Af}}$ & Feed concentration of component A \\
$\mathrm{T}(\mathrm{t})$ & Reactor temperature \\
$\mathrm{x}_{1}$ & Dimensionless concentration $\mathrm{x}_{1}(\mathrm{t})=\left(\mathrm{C}_{\mathrm{f}}-\mathrm{C}(\mathrm{t})\right) / \mathrm{C}_{\mathrm{f}}$ \\
$\mathrm{Q}$ & Process flowrate \\
$\mathrm{T}_{\mathrm{cf}}$ & Inlet coolant temperature \\
$\mathrm{T}_{\mathrm{f}}$ & Feed temerature \\
$\mathrm{T}_{\mathrm{j} 0}$ & Nominal feed temerature \\
$\gamma$ & Dimensionless activation energy $\gamma=\mathrm{E}_{\mathrm{a}} / \mathrm{RT}_{\mathrm{j} 0}$ \\
$\mathrm{x}_{2}$ & Dimensionless temperature $\mathrm{x}_{2}(\mathrm{t})=\left(\mathrm{T}(\mathrm{t})-\mathrm{T}_{\mathrm{j} 0}\right) \gamma / \mathrm{T}_{\mathrm{j} 0}$ \\
$\mathrm{u}$ & Dimensionless coolant temperature $\mathrm{u}(\mathrm{t})=\left(\mathrm{T}_{\mathrm{cf}}-\mathrm{T}_{\mathrm{j} 0}\right) \gamma / \mathrm{T}_{\mathrm{j} 0}$ \\
$\mathrm{H}$ & Dimensionless heat of reaction $\mathrm{H}=-\Delta \mathrm{HC}_{\mathrm{f}} \gamma / \mathrm{C}_{\mathrm{p}} \mathrm{T}_{\mathrm{j} 0}$ \\
$\Delta \mathrm{H}$ & Heat of reaction \\
$\mathrm{D}_{\mathrm{a}}$ & Damkohler number $\mathrm{D}_{\mathrm{a}}=\mathrm{Vk}_{0} \mathrm{e}^{\gamma} / \mathrm{Q}$ \\
$\mathrm{k}_{0}$ & Reaction velocity constant \\
$\mathrm{V}$ & Volume of tank \\
$\beta$ & Dimensionless cooling rate $\beta=\mathrm{UA} / \mathrm{QC}_{\mathrm{p}}$ \\
$\mathrm{A}$ & Heat transfer surface area \\
$\mathrm{E}_{\mathrm{a}} / \mathrm{R}$ & Activation energy \\
$\mathrm{U}$ & Overall heat transfer capacity \\
$\rho_{\mathrm{c}}$ & Liquid densities \\
$\mathrm{C}_{\mathrm{p}}$ & Volumetric heat capacities \\
\hline
\end{tabular}

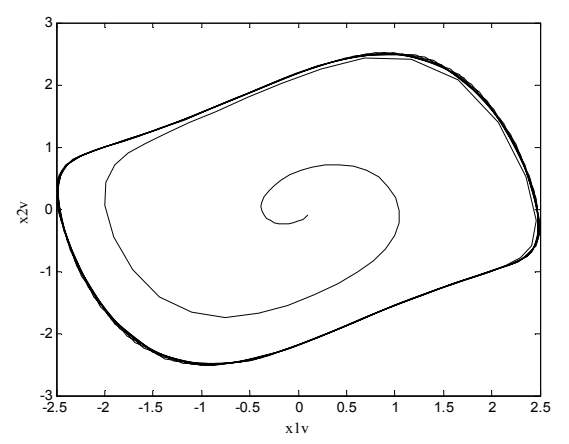

(a)
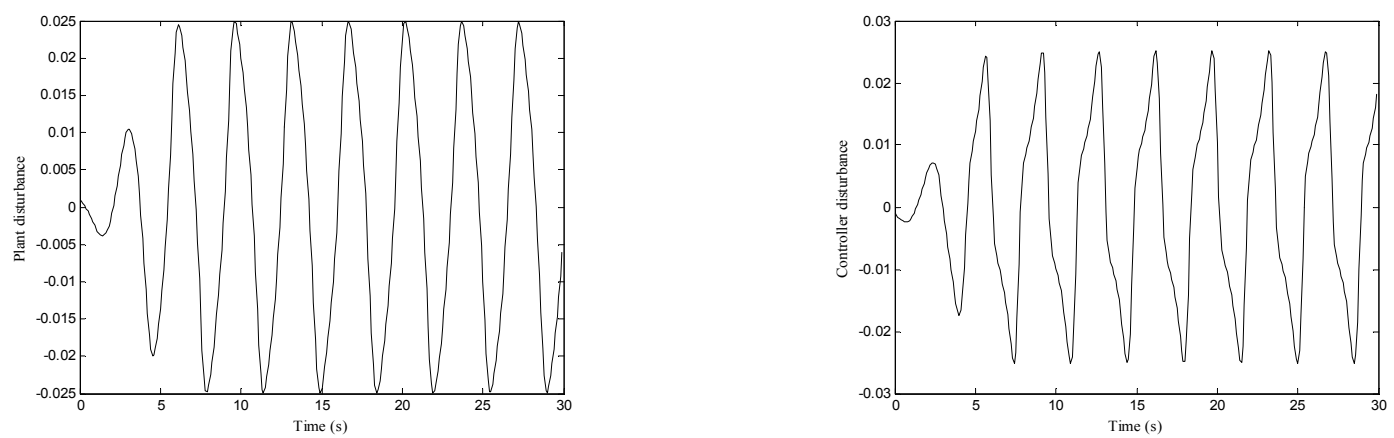

(b)

Figure 2: (a) Phase plane trajectory. (b) Disturbance signals $d_{i_{1} t_{-} 1}(t)$ and $d_{i_{s t} 2}(t)$. 


$$
\begin{aligned}
& \mathrm{x}_{1 \mathrm{v}}(\mathrm{k}+1)=\mathrm{x}_{1 \mathrm{v}}(\mathrm{k})+0.2 \cdot \mathrm{x}_{2 \mathrm{v}}(\mathrm{k}) \\
& \mathrm{x}_{2 \mathrm{v}}(\mathrm{k}+1)=-2 \cdot \mathrm{x}_{1 \mathrm{v}}(\mathrm{k})+\mathrm{x}_{2 \mathrm{v}}(\mathrm{k})- \\
& 0.1\left(\mathrm{x}_{1 \mathrm{v}}^{2}(\mathrm{k})-1\right) \mathrm{x}_{2 \mathrm{v}}(\mathrm{k}) \\
& \left\{\begin{array}{l}
\mathrm{d}_{\mathrm{ist}_{-} 1}(\mathrm{k})=0.01 \cdot \mathrm{x}_{1 \mathrm{v}}(\mathrm{k}) \\
\mathrm{d}_{\mathrm{ist}_{-} 2}(\mathrm{k})=0.01 \cdot \mathrm{x}_{2 \mathrm{v}}(\mathrm{k})
\end{array}\right.
\end{aligned}
$$

The diagram of plant control loop is plotted in Figure 3 that contains four blocks:

- optimization / tuning block characterized by GA;

- structural block representing the ROFLC;

- decisions block defining the performances criteria;

- system block to be controlled.

The interaction between these four blocks is summarized by:

1) generate initial population of chromosomes (each chromosome represents a fuzzy knowledge base);

2) projection of each chromosome on the specified structure of ROFLC;

3) for all chromosomes and all $\left(\underline{x}^{\mathrm{T}}, \underline{y}_{k}^{\mathrm{d}}\right) \in \Omega$ evaluate

fitness and classify the chromosomes according to their fitness.

Steps 2 and 3 are repeated until a maximum number of generations is carried out. After the evolution process, the final generation of population consists of highly fit strings that provide optimal or near optimal solutions.

In general, the objective of the control is to determine the process input $\underline{u}(\mathrm{k})$ such that $\lim _{\mathrm{k} \rightarrow \infty}\left|\underline{\mathrm{y}}(\mathrm{k})-\underline{\mathrm{y}}^{\mathrm{d}}(\mathrm{k})\right| \leq \varepsilon$

where $\varepsilon$ is a suitably chosen constant. That is the faster $\underline{y}(k)$ tracks the reference model $\underline{\mathrm{y}}^{\mathrm{d}}(\mathrm{k})$, the better the controller will perform (Bin-Da Liu et al., 2001).

In the CSTR example, the control objective is to have the system states $\left(\mathrm{x}_{1}, \mathrm{x}_{2}\right)$ follows a given reference trajectories $\left(\mathrm{x}_{1}^{\mathrm{d}}, \mathrm{x}_{2}^{\mathrm{d}}\right)$. Thus, the tracking errors must be as small as possible and the closedloop system must be globally stable and robust, i.e. all its parameters are uniformly bounded and the effect of the external disturbances is attenuated to a prescribed level.

\section{Proposed Optimal Controller}

The history of the Parallel Distributed Compensation (PDC) started with a model-based design process proposed by Tanaka and Sugeno (Tanaka and Sugeno, 1992). The PDC offers a scheme to design a fuzzy controller from the TS fuzzy model. Compared with the widely used PI, PD and PID controllers that require tuning only two or three parameters, the TS controller using PDC is extremely far removed from ease-of-use (Er et al., 2002). To overcome this disadvantage, a new control scheme called Proportional Parallel Distributed Compensation with Reduced Rule Base (PPDC_RRB), which can significantly reduce the number of parameters in PDC, is proposed in this work.

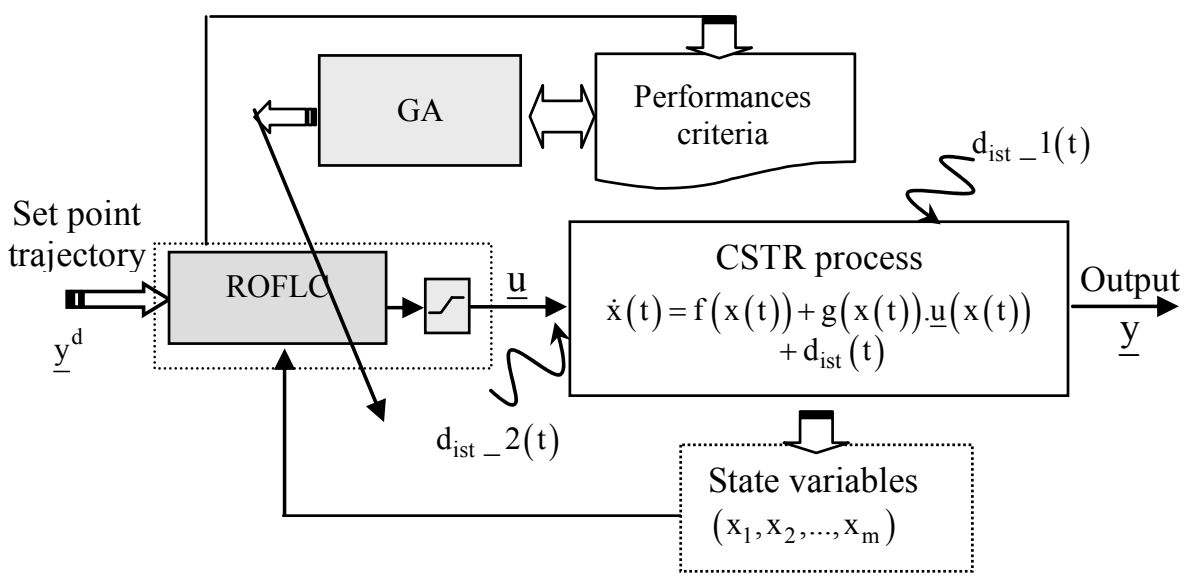

Figure 3: Control and optimization structure. 
PPDC_RRB Rule i:

$\underbrace{\mathrm{R}^{(i)}}_{i=1, \ldots, M}: \quad \operatorname{IF} x_{1}(t)$ is $A_{1}^{(i)} \ldots$. AND $x_{m}(t)$ is $A_{m}^{(i)}$ THEN $u=-K^{(i)} \cdot\{F^{(i)} \cdot \underbrace{\left(x(t)-x^{d}(t)\right)}_{\tilde{x}(t)}\} \quad \underline{\text { with }}\left\{\tilde{c}_{F}^{(i)}\right\}$

where,

\begin{tabular}{|c|c|}
\hline $\mathrm{A}_{1}^{(\mathrm{i})} \sim \mathrm{A}_{\mathrm{m}}^{(\mathrm{i})}$ & $\begin{array}{l}\text { are linguistic values of the fuzzy variables to express the universe of discourse } \\
\text { of the fuzzy set in the antecedent. }\end{array}$ \\
\hline$\underbrace{\mathrm{K}^{(\mathrm{i})}}_{\mathrm{i}=1, \ldots, \mathrm{M}}$ & represent the proportional coefficients, which differ with different control rules. \\
\hline $\mathrm{x}(\mathrm{t})=\left[\mathrm{x}_{1}(\mathrm{t}), \ldots, \mathrm{x}_{\mathrm{m}}(\mathrm{t})\right]^{\mathrm{T}}$ & is a vector input (system states). \\
\hline$x^{d}(t)=\left[x_{1}^{d}(t), \ldots, x_{m}^{d}(t)\right]^{T}$ & is a vector of set point trajectory (desired input). \\
\hline $\mathrm{F}^{(\mathrm{i})}=\left[\mathrm{p}_{1}^{(\mathrm{i})}, \ldots, \mathrm{p}_{\mathrm{m}}^{(\mathrm{i})}\right]$ & $\begin{array}{l}\text { is the vector parameters set of the Takagi-Sugeno fuzzy model of the } i^{\text {th }} \text { rule } \\
\text { (in this work } \mathrm{p}_{0}=0 \text { ). }\end{array}$ \\
\hline$\left\{\tilde{\mathrm{c}}_{\mathrm{F}}^{(\mathrm{i})}\right\}$ & $\begin{array}{l}\text { represents the certainty factor (K. Belarbi et al., 2005; Chi-Ho Lee et al., 2003) of } \\
\text { the } i^{\text {th }} \text { rule. The latter can take only two values; either } 0 \text { or } 1\left(\left\{\tilde{c}_{\mathrm{F}}^{(\mathrm{i})}\right\}=1 / 0 \text {, }\right. \\
\text { characterizes enabled/disabled rule). }\end{array}$ \\
\hline $\mathrm{u}$ & represents the output variable. \\
\hline with & is the operator modelling the weighting of a rule (Rafael Alcaléa et al., 2006). \\
\hline
\end{tabular}

The overall state feedback fuzzy controller is represented by

$$
\begin{aligned}
& \mathrm{u}(\mathrm{t})=\frac{-\sum_{\mathrm{i}=1}^{\mathrm{i}=\mathrm{M}} \mathrm{w}^{(\mathrm{i})}(\mathrm{x}(\mathrm{t})) \cdot \tilde{\mathrm{c}}_{\mathrm{F}}^{(\mathrm{i})} \cdot \mathrm{K}^{(\mathrm{i})} \cdot\left\{\mathrm{F}^{(\mathrm{i})} \cdot \tilde{\mathrm{x}}(\mathrm{t})\right\}}{\sum_{\mathrm{i}=1}^{\mathrm{i}=\mathrm{M}} \mathrm{w}^{(\mathrm{i})}(\mathrm{x}(\mathrm{t}))}=
\end{aligned}
$$

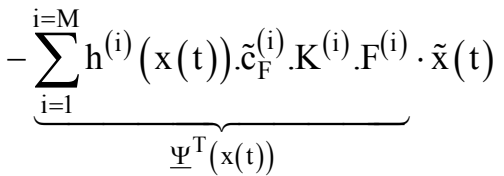

where

$$
\begin{aligned}
& \underbrace{\mathrm{w}^{(\mathrm{i})}(\mathrm{x}(\mathrm{t}))}_{\mathrm{i}=1, \ldots, M}=\prod_{j=1}^{\mathrm{j}=\mathrm{m}} \mu_{\mathrm{ij}}\left(\mathrm{x}_{\mathrm{j}}(\mathrm{t})\right),\left\{\begin{array}{l}
\sum_{\mathrm{i}=1}^{\mathrm{i}=\mathrm{M}} \mathrm{w}^{(\mathrm{i})}(\mathrm{x}(\mathrm{t}))>0 \\
\mathrm{w}^{(\mathrm{i})}(\mathrm{x}(\mathrm{t})) \geq 0
\end{array}\right. \\
& \mathrm{h}^{(\mathrm{i})}(\mathrm{x}(\mathrm{t}))=\frac{\mathrm{w}^{(\mathrm{i})}(\mathrm{x}(\mathrm{t}))}{\sum_{\mathrm{i}=1}^{\mathrm{i}=\mathrm{M}} \mathrm{w}^{(\mathrm{i})}(\mathrm{x}(\mathrm{t}))},\left\{\begin{array}{l}
\sum_{\mathrm{i})}^{\mathrm{i}=\mathrm{M}} \mathrm{h}^{(\mathrm{i})}(\mathrm{x}(\mathrm{t}))=1 \\
\mathrm{~h}^{(\mathrm{i})}(\mathrm{x}(\mathrm{t})) \geq 0
\end{array}\right.
\end{aligned}
$$

$\mu_{i j}\left(x_{j}(t)\right)$ is the grade of membership of $x_{j}(t)$ in fuzzy set $A_{j}^{(i)}$ and $h^{(i)}(x(t))$ denotes the normalized weight of each fuzzy rule.
From the expression (8), the optimal control law will be represented by

$$
\mathrm{u}(\mathrm{t})=-\underline{\Psi}^{\mathrm{T}}(\mathrm{x}(\mathrm{t})) \cdot \tilde{\mathrm{x}}(\mathrm{t})
$$

where $\underline{\Psi}^{T}(x(t))$ (resp. $\left.u(t)\right)$ is the nonlinear feedback gain vector due to the nonlinear nature of the Takagi-Sugeno fuzzy system.

The problem considered in this paper is to find the optimal PPDC_RRB controller, i.e. the optimal nonlinear gain $\Psi^{\mathrm{T}}(\mathrm{x}(\mathrm{t}))$ based on the following objectives:

1) minimize the error absolute between the output signals and reference models $\left(\mathrm{J}_{\text {Error }}\right)$;

2) reduce the quantity of the energy of the control signals (coolant flow rate) applied to the system ( $\left.\mathrm{J}_{\text {Energy }}\right)$;

3) minimize the number of fuzzy rules $\left(\mathrm{J}_{\text {Rule_Base }}\right)$.

These objectives are selected with respect to the imposed constraints (fuzzy constraints membership function and system control constraints). As indicates by the following formula:

Minimize J, with 


$$
\begin{aligned}
& \mathrm{J}=\overbrace{\sum_{\mathrm{m}=1}^{\max \mathrm{t}} \underbrace{\left(\mathrm{C}^{(1)} \cdot\left(\left|\mathrm{x}_{1}^{\mathrm{d}}(\mathrm{k})-\mathrm{x}_{1}(\mathrm{k})\right|+\left|\mathrm{x}_{2}^{\mathrm{d}}(\mathrm{k})-\mathrm{x}_{2}(\mathrm{k})\right|\right)\right)}_{(1)}}^{\mathrm{J}_{\text {Error }}}+
\end{aligned}
$$

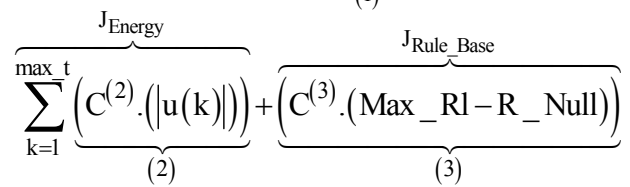

Subject to

$$
\begin{aligned}
& \begin{cases}\sum_{\mathrm{i}}\left(\tilde{\mathrm{c}}_{\mathrm{F}}^{(\mathrm{i})}\right) \geq 1 & \text { (in Eq. 7) } \\
\sum_{\mathrm{i}=1}^{\mathrm{i}=\mathrm{M}} \mathrm{W}^{(\mathrm{i})}(\mathrm{x}(\mathrm{t}))>0 & \text { (in Eq. 8) }\end{cases} \\
& \left\{\begin{array}{c}
\mathrm{C}^{(1)}, \mathrm{C}^{(2)}, \mathrm{C}^{(3)} \geq 0 \\
\& \\
\mathrm{C}^{(1)}+\mathrm{C}^{(2)}+\mathrm{C}^{(3)} \leq 1
\end{array}\right.
\end{aligned}
$$

where $\mathrm{C}^{(1)}, \mathrm{C}^{(2)}$ and $\mathrm{C}^{(3)}$ are dynamic factors of weightings characterizing the precision, the energy and the complexity of the controller. They represent the relative importance of each objective. A particular case is, where $\mathrm{C}^{(1)}+\mathrm{C}^{(2)}+\mathrm{C}^{(3)}=1$. There will be a convex combination of the conceptual factors in this situation. The set of priorities is measured by the capacity of the controller to carry out effectively the aims had by the designer. In our case, the objectives are classified according to the degree of importance of the conceptual factors:

- accuracy 'efficiency' and stability ;

- the reduction of complexity of the control law;

- the reduction of the effort of control (energy) to apply to the process.

max_t is the maximum of time and Max_Rl is the maximal number of rules. $R_{-}$Null is the number of activated rules, defined as

$\mathrm{R}_{-}$Null $=\sum_{\mathrm{i}=1}^{\mathrm{Max}}{ }^{\mathrm{Rl}}\left(\tilde{\mathrm{c}}_{\mathrm{F}}^{(\mathrm{i})}\right)$

The discrete step values of $\mathrm{u}$ equispaced over process operation time are considered as optimization variables. These step values form a control vector $\mathrm{u}^{\mathrm{opt}}$. In order to take into account the constraints on the manipulated variables, the following saturation function was defined

$$
\underline{u}= \begin{cases}u_{\max } & \text { if } u_{\max } \prec u^{*} \\ u^{*} & \text { if } u_{\min } \leq u^{*} \leq u_{\max } \\ u_{\min } & \text { if } u^{*} \prec u_{\min }\end{cases}
$$

where $\mathrm{u}_{\min }$ and $\mathrm{u}_{\max }$ are the lower and upper bound of the saturation elements, respectively.

\section{GENETIC LEARNING ALGORITHM}

The concrete steps realizing the optimization of PPDC_RRB (PPDC_RRB $\equiv$ ROFLC) is as follows:

\section{Step 1: Initialization}

Create some chromosomes randomly. Each chromosome is denoted as a group of controller parameters. The difference between the genetic algorithms used in the literature resides in coding levels of the coding (binary, integer or real) and the genetic operators adapted to every coding type (Sharma et al., 2003).

The use of the mixed coding, binary-floating, multiparametered and concatenated permits to construct the chromosome of the GA. This technique allows or encourages the coding and the successive juxtaposition of the different parameters. Every chromosome can represent a solution of the problem, that is, a fuzzy optimal knowledge base. Figure 4 and Table 2 represent the chromosomes genes and its coding type, respectively.

The partitions are symmetric about the membership function $\mathbf{Z E}$. This approach simplifies the computation while typically giving robust and satisfactory results. It also simplifies the optimisation testing of the GA (Soukkou et al., 2008). We assume that MFs are strictly monotone decreasing (or increasing) and continuous functions with respect to $x_{i}$, while $x_{k}^{L}$ is a maximal left tolerance limit to $\mathrm{b}_{\mathrm{k}}$ and $\mathrm{x}_{\mathrm{k}}^{\mathrm{R}}$ is a maximal right tolerance limit to $b_{k}$. The expressions of different fuzzy constraints MFs used in the fuzzy partitions are given by

$$
\underbrace{\overbrace{\mu_{A_{i}^{j}}\left(x_{i}\right)}^{Z E}}_{\text {Fuzzy Equal }}= \begin{cases}0 & \text { if } x_{i}<b_{i}-x_{i}^{L} \\ \frac{x_{i}-\left(b_{i}-x_{i}^{L}\right)}{x_{i}^{L}} & \text { if } b_{i}-x_{i}^{L} \leq x_{i} \leq b_{i} \\ 1-\frac{x_{i}-b_{i}}{x_{i}^{R}} & \text { if } x_{i}=b_{i} \\ 0 & \text { if } b_{i} \leq x_{i} \leq b_{i}+x_{i}^{R}\end{cases}
$$

In Figure $4, \iota_{\mathrm{ZE} 1}$ and $\iota_{\mathrm{ZE} 2}$ are the widths of the universes of discourses of the fuzzy subsets $\mathbf{Z E}$ of the input variables $\mathrm{x}_{1}$ and $\mathrm{x}_{2}$, respectively. $K_{\mathrm{x} 1,2}$ represent the scaling factors of the input variables.

The main purpose of introducing the GA to the design of a fuzzy controller is not only to use the robust and global benefits of GA but also to develop a systematic design approach of the fuzzy controller. 

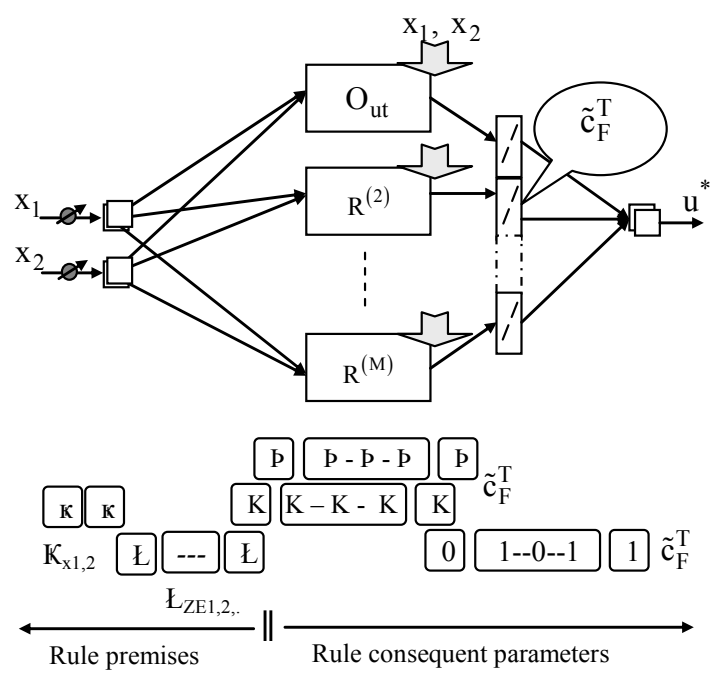

Figure 4: Chromosome structure and corresponding rule base.

Table 2: GA coding-type

\begin{tabular}{|l|l|}
\hline Parameter & Coding-type \\
\hline $\mathrm{K}_{\mathrm{x} 1,2} ; \mathrm{p}_{1,2}^{(\mathrm{i})} ; \mathrm{K}^{(\mathrm{i})} ; \mathrm{L}_{\mathrm{ZE} 1,2,}$ & Real \\
$\tilde{\mathrm{c}}_{\mathrm{F}}^{\mathrm{T}}$ & Binary \\
\hline
\end{tabular}

\section{Step 2: Evaluation of Fitness Value}

Calculate the fitness value of each chromosome in the population. In this application the objective function (fitness) responsible for the ordering of the chromosomes in the population is:

$$
\mathrm{F}_{\mathrm{it}}=(1+\mathrm{J})^{-1}
$$

where, $\mathrm{J}$ is the optimisation index (Eq. 10). The optimisation of the PPDC_RRB is to find the 'best' structure and the parameters, i.e. an optimal fuzzy knowledge base, which can be represented as an extremum problem of optimisation index.

\section{Step 3: Selection}

Select two individuals for reproduction. The probability of selection for each individual is calculated as:

$$
\mathrm{P}_{\mathrm{i}}(\text { select })=\mathrm{F}_{\mathrm{it}}\left(\text { Parent }_{\mathrm{i}}\right) / \sum_{\mathrm{i}=1}^{\text {Pop }} \sum_{\mathrm{it}}^{\text {size }} \mathrm{F}_{\mathrm{i}}\left(\text { Parent }_{\mathrm{i}}\right)
$$

where $F_{i t}\left(\right.$ Parent $\left._{i}\right)$ represent the fitness of the $i^{\text {th }}$ parent in the population.

\section{Step 4: Reproduction:}

Create new individuals by the application of crossover and mutation operators.

- Crossover: The crossover operator is the main method to produce new chromosome. Exchange the genetic materiel between $P_{i}$ and $P_{j}$ and then get two individuals $\mathrm{P}_{\mathrm{i}}^{\prime}$ and $\mathrm{P}_{\mathrm{j}}^{\prime}$. Figure 5 illustrates the different standard forms of crossover operator.

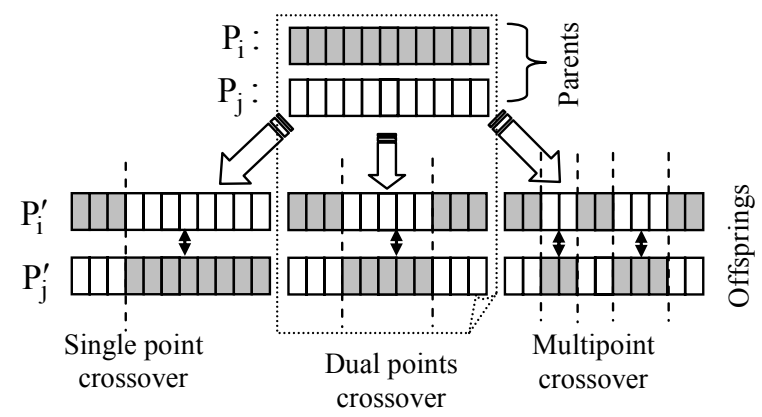

Figure 5: Crossover. 
- Mutation: Mutation is applied to increase the diversity of the population to enhance the chance forGA to escape from local optima. The actual process of mutation depends on the coding form. In binary coding part of chromosome, mutation only performs 1-bit flip, i.e., the bit value changes from ' 0 ' to ' 1 ' or from ' 1 ' to ' 0 '. If the mutation takes place in the real coded part, we use the nonlinear mutation (Lo and Sadegh, 2003; Zhi-Hua Cui et al., 2003). The nonlinear mutation operator is defined as follows:

$\mathrm{Ch}_{\mathrm{v}}^{\mathrm{Gen}}=\left(\mathrm{V}_{1}, \cdots, \mathrm{V}_{\mathrm{K}}, \cdots, \mathrm{V}_{\mathrm{m}}\right)$

where Gen is the number of generation and $V_{i}(i=1$, ..., m) are codes in real format of the variables constituting the chromosome $\mathrm{Ch}$. Suppose that $\mathrm{V}_{\mathrm{K}}$ be the element selected to the operation of mutation, the resulting chromosome is:

$$
\begin{aligned}
& \mathrm{S}_{\mathrm{v}}^{\mathrm{Gen}}=\left(\mathrm{V}_{1}, \cdots, \mathrm{V}_{\mathrm{K}}, \cdots, \mathrm{V}_{\mathrm{m}}\right) ; \\
& \mathrm{S}_{\mathrm{v}}^{\mathrm{Gen}+1}=\left(\mathrm{V}_{1}, \cdots, \mathrm{V}_{\mathrm{K}}^{\prime}, \cdots, \mathrm{V}_{\mathrm{m}}\right) \\
& \mathrm{V}_{\mathrm{K}}^{\prime}=\left\{\begin{array}{l}
\mathrm{V}_{\mathrm{K}}+\Delta\left(\text { Gen, } \mathrm{U}_{\mathrm{B}}-\mathrm{V}_{\mathrm{K}}\right): \text { if } \mathrm{r}<0.5 \\
\mathrm{~V}_{\mathrm{K}}-\Delta\left(\text { Gen, } \mathrm{V}_{\mathrm{K}}-\mathrm{L}_{\mathrm{B}}\right): \text { if } \mathrm{r} \geq 0.5
\end{array}\right.
\end{aligned}
$$

where $r$ is a random number $\in[0,1], \mathrm{U}_{B}$ and $\mathrm{L}_{\mathrm{B}}$ is the upper and lower bound of the domain of variation of the variable $V_{K}$, respectively.

$$
\Delta(\text { Gen, } y)=y \cdot\left(\left(1-\tau^{1-\frac{G e n}{\text { Max_Gen }}}\right)^{b}\right)
$$

where $\tau$ is a random number $\in[0,1]$ and $b$ is a system parameter which determining the degree of non-uniformity, which is taken to be three in this application.

\section{Step 5: Elitism}

To put a limitation to the genetic divergence, one of the elitism strategies has been introduced. The latter, based on the technic of the steady-state selection, permits the constructionof a more effective new generation than the previous (the best member in last generation (Gen-1) will be substituted into the worst member in the actual generation).

If a stop criterion is satisfied, return the chromosome with the best fitness. Otherwise, go to step 2.

\section{SIMULATION}

\section{Control of CSTR by PPDC_RRB}

The objective of the control is to generate a sequence of actions $\mathrm{u}_{\min } \leq \mathrm{u} \leq \mathrm{u}_{\max }$ allowing the CSTR system to follow the desired regulation trajectory given by (Chia-Feng Juang, 2007)

$$
\begin{aligned}
& \mathrm{x}_{1}^{\mathrm{d}}(\mathrm{k})=\left\{\begin{array}{cc}
0.4472 & \mathrm{k} \leq 100 \\
0.7646 & 100<\mathrm{k} \leq 200 \\
0.4472 & 200<\mathrm{k} \leq 300
\end{array}\right. \text { and } \\
& \mathrm{x}_{2}^{\mathrm{d}}(\mathrm{k})=\left\{\begin{array}{cc}
2.7520 & \mathrm{k} \leq 100 \\
4.7052 & 100<\mathrm{k} \leq 200 \\
2.7520 & 200<\mathrm{k} \leq 300
\end{array}\right.
\end{aligned}
$$

This trajectory repeats with each 300 samples, which represents one period. The PPDC_RRB is initially characterized by 5 fuzzy subsets for the first input and 5 fuzzy subsets for the second input. This gives 25 rules.

Initially every chain of the population will contain $25 * 2+25+2+2$ real numbers +25 binary digits $(25 * 2$ for TS parameter consequences, 25 for proportional coefficients, 2 genes for universe of discourses of input variables, 2 genes represents the scaling factors of the input variables and 25 bits represent the certainties factors). Specifications of the GA mechanisms are listed in Table 3.

In this application, $\underbrace{\mathrm{C}^{(\mathrm{i})}}_{\mathrm{i}=1,2,3}$ and max_t in (10) equal to $(0.50(50 \%), 0.15(15 \%), 0.35(35 \%))$ and 300 , respectively.

The general structure of the genetic learning algorithm is shown in Figure 6. Figure 7 indicates the evolution of the fitness function. The number of rules enabled during the evolution of GA is represented in Figure 8. 
Table 3: Specifications of the GA

\begin{tabular}{|l|l|}
\hline Parameters & Value/Type \\
\hline Population Size & 10 \\
Max_Gen & 500 \\
Representation & Mixed binary-real \\
Initialization & Random \\
Scaling factors $\mathrm{K}_{\mathrm{x} 1,2}$ & {$[5,20]$} \\
& ] $\left.0,10 \times \max \left(\left|u_{\min }\right|,\left|u_{\max }\right|\right)\right]$ \\
Proportional coefficients $\mathrm{K}^{(\mathrm{i})}$ & {$[-1,1]$} \\
TS parameters and $\mathrm{L}_{\mathrm{ZE} 1,2}$ & Dual-point with probability $\mathrm{P}_{\mathrm{c}}=0.8$ \\
Crossover operator & Mixed, uniform and non-uniform with probability $\mathrm{P}_{\mathrm{m}}=0.01$ \\
Mutation operator & \\
\hline
\end{tabular}

\begin{tabular}{l}
\hline Procedure GA(Gen) \\
\hline\{ \\
Initialisation(); \\
Evaluation(); \\
Keep_The_Best_Individual(); \\
Gen =0; \\
Repeat \{ \\
Selection(); \\
Crossover(); \\
Nonlinear mutation(); \\
Evaluation(); \\
Elitism strategies(); \\
Gen++;\} \\
Until (Gen < Max_Gen); \\
\{
\end{tabular}

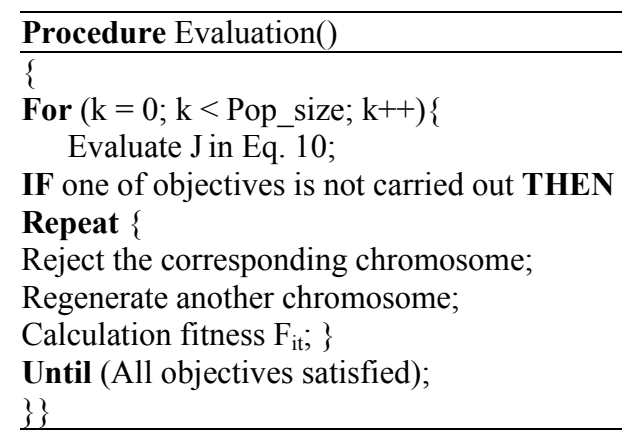

Figure 6: General structure of genetic learning algorithm.

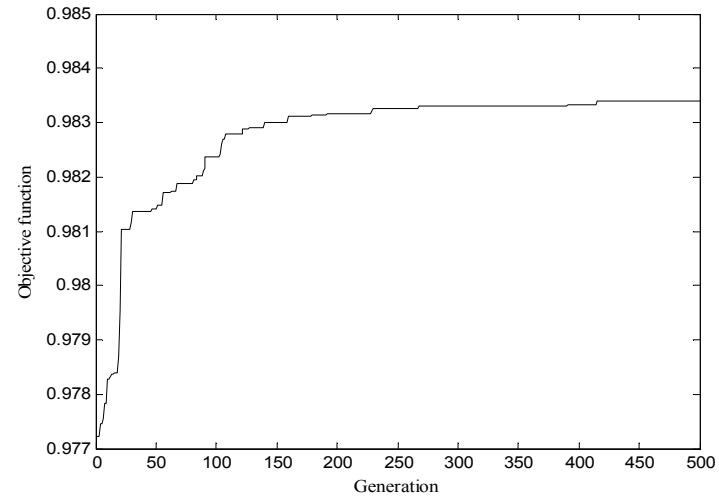

Figure 7: Evolution of the fitness function.

Only three rules remain at the end of GA execution, i.e. the certainties factors of rules $\tilde{\mathrm{c}}_{\mathrm{F}}^{(19)}$ and $\tilde{\mathrm{c}}_{\mathrm{F}}^{(20)}$ are equal to the unit, as indicated in the Table 4. Figure 9 shows the trajectory convergence to the reference model from the initial conditions $\left(x_{1}(0), x_{2}(0)\right)=(0.144,0.8862) \quad($ ChiaFeng Juang, 2007).

The feedback vector of gains in equation (7)

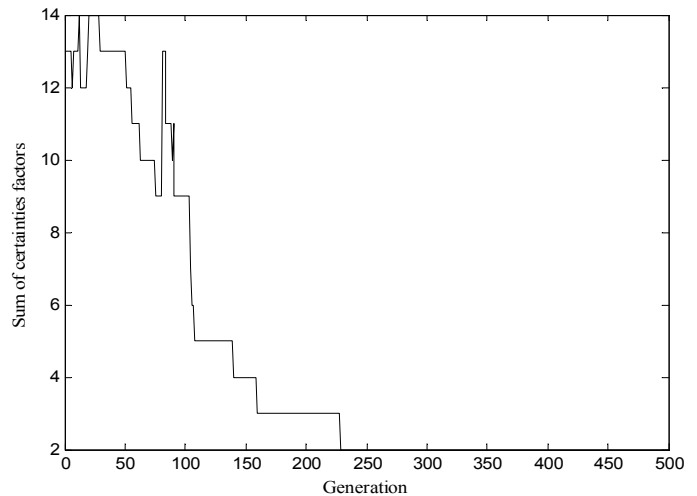

Figure 8: Evolution of the enabled rule numbers.

obtained at the end of the GA execution are given by

$$
\begin{aligned}
& \mathrm{K}^{(19)}=\left[\begin{array}{ll}
99.9901 & -46.3158
\end{array}\right] \text { and } \\
& \mathrm{K}^{(20)}=\left[\begin{array}{ll}
-29.5662 & -69.2295
\end{array}\right]
\end{aligned}
$$

By analyzing the Figure 9, it can be remarked that the proposed design strategy accomplishes the design requirements effectively. 
Table 4: The rule base of PPDC_RRB

\begin{tabular}{|l|l|l|l|l|c|}
\hline \multicolumn{1}{|c|}{$\mathrm{X}_{2} \mathrm{X}_{1}$} & NB & NM & ZE & PM & PB \\
\hline NB & & & & & \\
NM & & & & & \\
ZE & & & & $\mathrm{u}^{(19)}$ & $\mathrm{u}^{(20)}$ \\
PM & & & & & \\
PB & & & & \\
\hline
\end{tabular}

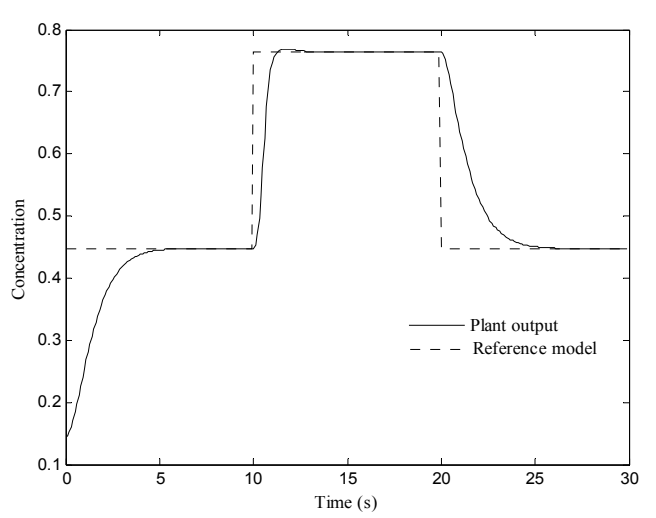

(a)

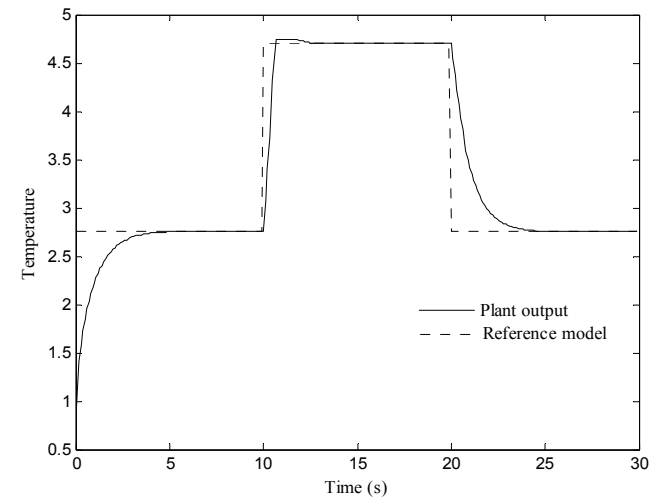

(b)

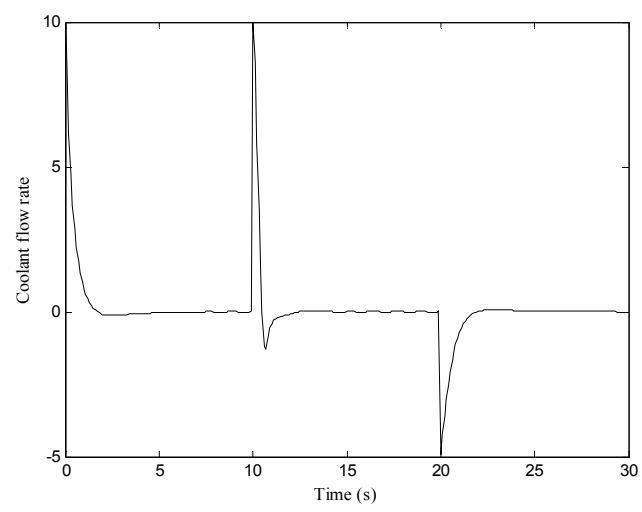

(c)

Figure 9: System states using PDC_RRB: (a) The state $x_{1}(t)$ and its desired value $y_{1}^{d}(t)$.

(b) The state $x_{2}(t)$ and its desired value $y_{2}^{d}(t)$. (c) Control signal.

\section{Control of CSTR by PD_GO}

The continuous form of a PD controller with input $e$ and output $u$ is given by

$u(t)=K_{P}\left(e(t)+T_{d} \frac{d e(t)}{d t}\right)$

where $K_{P}$ is the proportional gain and $T_{d}$ is the derivative time constant. We ca also rewrite (22) as

$u(t)=K_{P} \cdot e(t)+K_{D} \cdot \frac{d e(t)}{d t}=F_{P D \_G O}(e(t))$ where $K_{D}=K_{P} \cdot T_{d}$ is the derivative gain. Figure 10 displays the PD controller design for CSTR process.

The structure of chromosome adapted for the PDGO controller contains two real values, one for the proportionality gain and the other for the derivative gain. The plant controller is defined by

$$
\mathrm{u}(\mathrm{t})=\mathrm{F}_{\mathrm{PD} \_} \mathrm{GO}_{-} 1\left(\mathrm{e}_{1}(\mathrm{t})\right)+\mathrm{F}_{\mathrm{PD} \_\mathrm{GO} \_}\left(\mathrm{e}_{2}(\mathrm{t})\right)
$$

where

$$
\mathrm{e}_{1}(\mathrm{k})=\mathrm{x}_{1}^{\mathrm{d}}(\mathrm{k})-\mathrm{x}_{1}(\mathrm{k}) \text { and } \mathrm{e}_{2}(\mathrm{k})=\mathrm{x}_{2}^{\mathrm{d}}(\mathrm{k})-\mathrm{x}_{2}(\mathrm{k})
$$


represent the concentration error and temperature error of CSTR process, respectively.

The GA-PI characteristics are summarized in Table 5. The fitness function chooses in this part of paper is given by

$$
\mathrm{F}_{\mathrm{it}}=\left(1+\sum_{\mathrm{k}=1}^{300}\left(\begin{array}{l}
10^{-4} \cdot\left|\mathrm{e}_{1}(\mathrm{k})\right|+10^{-4} \cdot\left|\mathrm{e}_{1}(\mathrm{k})\right|+ \\
10^{-4} \cdot|\mathrm{u}(\mathrm{k})|
\end{array}\right)\right)^{-1}
$$

Figures 11 and 12 show the convergence trajectories for performances index and control gains $\underbrace{\mathrm{K}_{\mathrm{Pi}}, \mathrm{K}_{\mathrm{Di}}}_{\mathrm{i}=1,2}$ of the PD_GO controller, respectively. The performances of the PD_GO controller are presented by Figures 13 (a), (b) and (c).

By analyzing the Figures 9 and 13, it can be remarked that the proposed design strategy accomplishes the design requirements effectively. The nonlinear optimal controller PPDC_RRB presents good performances. However, a PD_GO controller is effective (see Figures 14 and 15), which justifies the efficiency and robustness of the proposed conception method.

The real-coded GA is robust, accurate and efficient because the floating-point representation is conceptually closest to the real design space and the sting length is reduced to the number of design variables.

The fuzzy optimal topology designed (via the genetic optimization) in this paper is very simple and contains a minimal number of rules. The advantages of the proposed designing methodologies are that it reduces the number of rules and the design complexity of the fuzzy systems. The proposed method is able to reduce 25 rules to 3 maintaining almost the same level of desired performances.

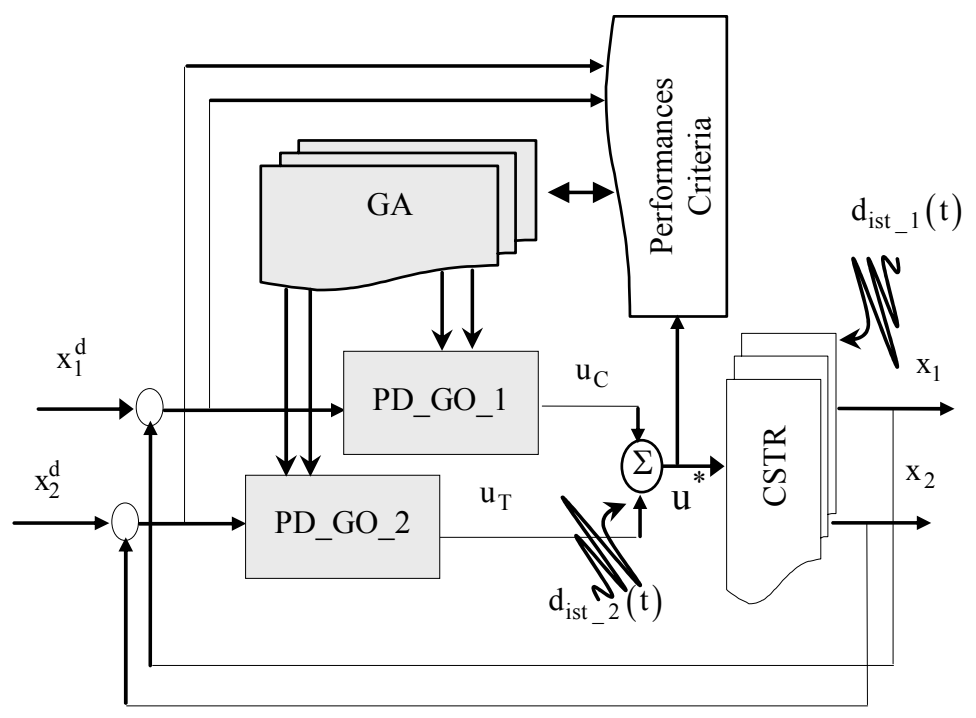

Figure 10: Control and optimization structure.

Table 5: Specifications of the PD_GO

\begin{tabular}{|l|c|}
\hline Characteristic & value \\
\hline Population Size & 100 \\
Max_Gen & 500 \\
Coding chromosome & Real \\
Gain factors $\left\{\left(\mathrm{K}_{\mathrm{P} 1}, \mathrm{~K}_{\mathrm{D} 1}\right),\left(\mathrm{K}_{\mathrm{P} 2}, \mathrm{~K}_{\mathrm{D} 2}\right)\right\}$ & ] $0.0,100.0]$ \\
Selection process & Tournament \\
Crossover single point & $\mathrm{P}_{\mathrm{c}}=0.5$ \\
Nonlinear mutation $(\mathrm{Eq} .18)$ & $\mathrm{P}_{\mathrm{m}}=0.25$ \\
\hline
\end{tabular}




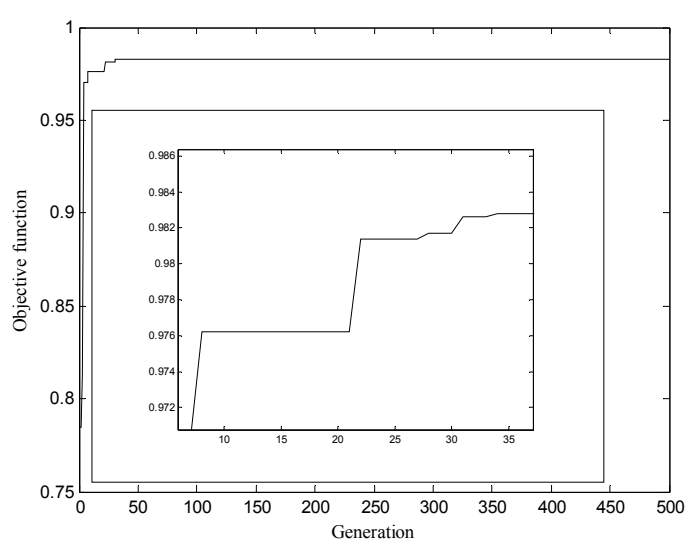

Figure 11: Fitness function.

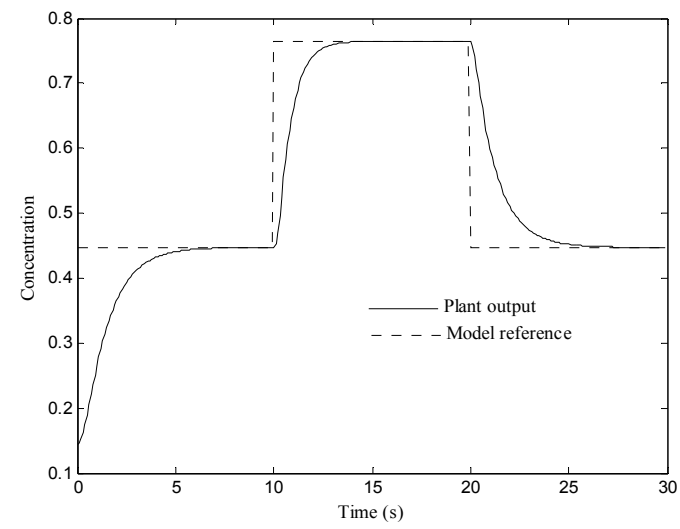

(a)

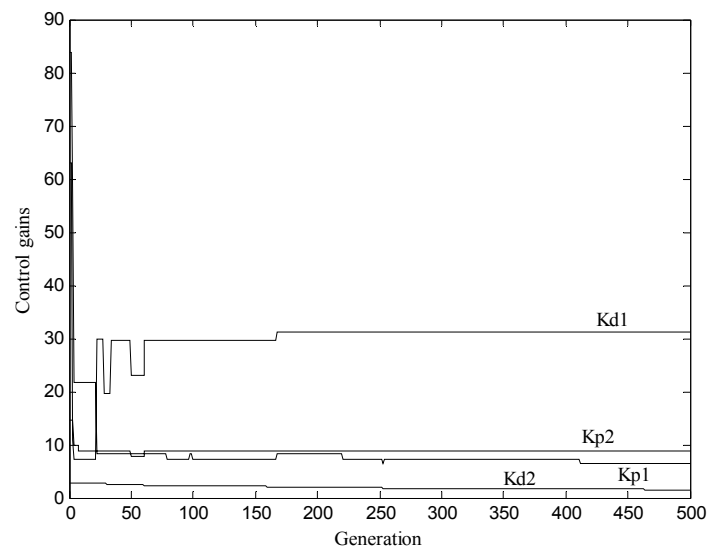

Figure 12: Convergence of PD control gains $\underbrace{\mathrm{K}_{\mathrm{Pi}}, \mathrm{K}_{\mathrm{Di}}}_{\mathrm{i}=1,2}$.

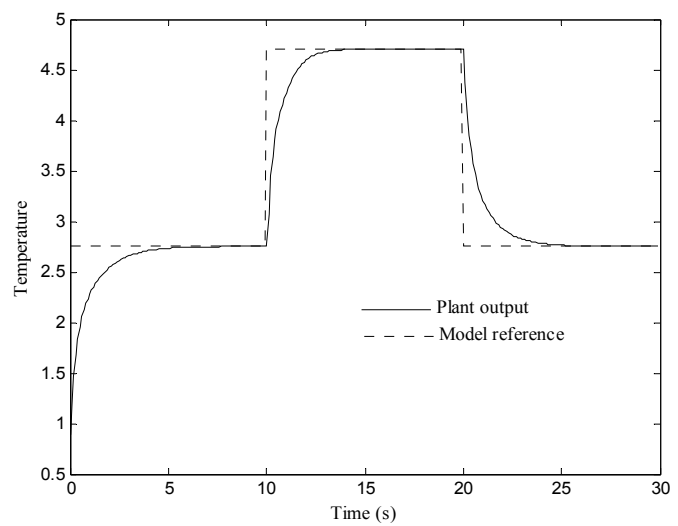

(b)

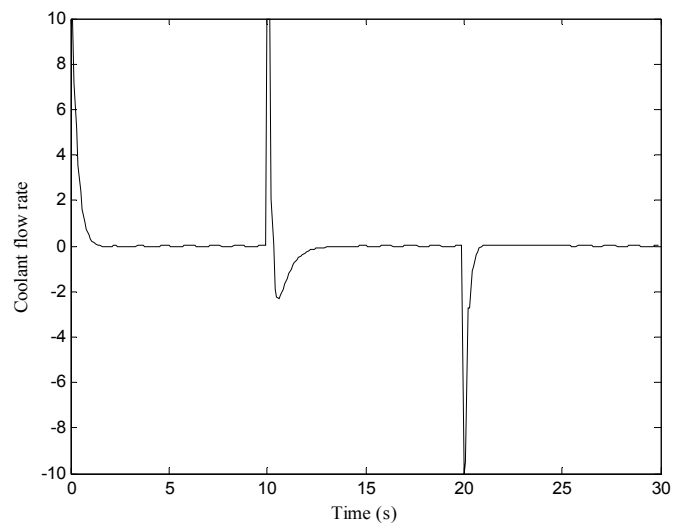

(c)

Figure 13: System states using PD_GO: (a) The state $x_{1}(t)$ and its desired value $y_{1}^{d}(t)$. (b) The state $x_{2}(t)$ and its desired value $y_{2}^{d}(t)$. (c) Control signal. 


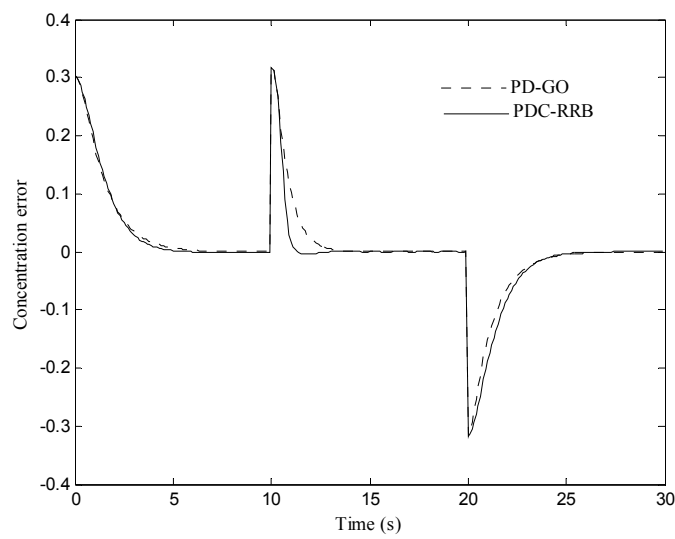

Figure 14: Concentration error tracking.

\section{CONCLUSION}

This paper contributes a new alternative for the synthesis of fuzzy optimal controller with reduced rule base. The genetic learning algorithm is proposed for constructing a robust fuzzy controller. Simulations demonstrate that the resultant optimal controller gives good performance.

The newly proposed controller has been applied to CSTR control system. The efficiency of this approach is measured by the controller's capacity to achieve the goal aimed by the control loop. One can say that this controller manages to achieve the desired task, which justifies the efficiency and the robustness of the proposed conception method.

Based on the simulation results, the following main conclusions can be stated about the proposed PPDC_RRB:

- It is easy, and it exploits the fine abilities and advantages of the fuzzy logic and genetic algorithms.

- A reduced number of fuzzy rules was sufficient to achieve the optimal control objective, which permits possible real-time implementations.

\section{REFERENCES}

Alcaléa R., Alcaléa-Fdez J., Casillas J., Cordéon O., Herrera F., Hybrid learning models to get the interpretability-accuracy trade-off in fuzzy modelling, Soft Computing, 10, 717-734 (2006).

Aoyama A.; Doyle III, F.J.; Venkatasubramanian, V., A fuzzy neural-network approach for nonlinear process control, Engineering Applications of Artificial Intelligence, 8, No. 5, 483-498 (1995).

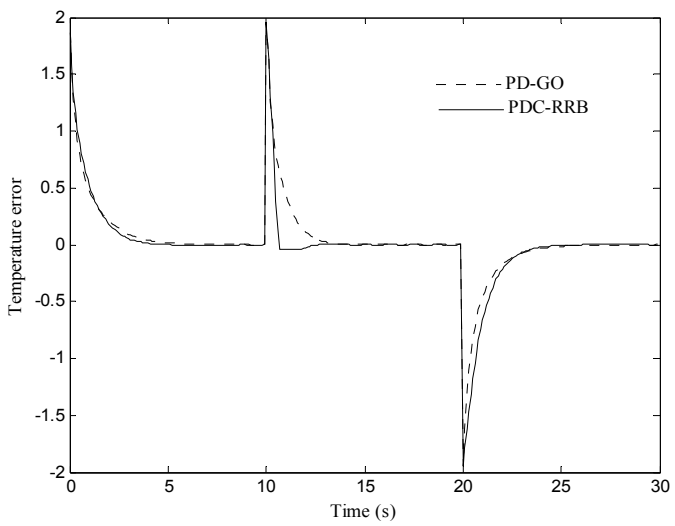

Figure 15: Temperature error tracking.

Belarbi K., Titel F., Bourebia W., Benmahammed K., Design of Mamdani fuzzy logic controllers with rule base minimisation using genetic algorithm, Engineering Applications of Artificial Intelligence, 18, No. 7, 875-880 (2005).

Bin-Da Liu, Chuen-Yau Chen and Ju-Ying Tsao, Design of adaptive fuzzy logic controller based on Linguistic-Hedge concepts and genetic algorithms, IEEE Transactions on Systems, Man, and Cybernetics-Part B: Cybernetics, 31, No. 1, 32-53 (2001).

Casillas J., Cordon O., del Jesus M. J. and Herrera F., Genetic Tuning of Fuzzy Rule Deep Structures Preserving Interpretability and Its Interaction with Fuzzy Rule set Reduction, IEEE Transactions on Fuzzy Systems, 13, No. 1, 13-29 (2005).

Cheng-Wu Chen, Stability conditions of fuzzy systems and its application to structural and mechanical systems, Advances in Engineering Software, 37, 624-629 (2006).

Chih-Hsun Chou, Genetic algorithm-based optimal fuzzy controller design in the linguistic space, IEEE Transactions on Fuzzy Systems, 14, No. 3, 372-385 (2006).

Chia-Feng Juang, I-Fang Chung, Recurrent fuzzy network design using hybrid evolutionary learning algorithms, Neurocomputing, 44, 1-10 (2007).

Chi-Ho Lee, Ming Yuchi and Jong-Hwan Kim, Two phase optimization of Fuzzy Controller by Evolutionary Programming, The 2003 Congress on Evolutionary Computation, 2003, CEC '03, 2003 IEEE, 3, 8-12 Dec. 2003, 1949-1956 (2003).

Er M. J., Lin D. H., A new approach for stabilizing nonlinear systems with time delays, International 
Journal of Intelligent Systems, 17, 289-302 (2002).

Goldberg, D.E. Algorithmes génétiques: Exploration, Optimisation et Apprentissage Automatique, Addison-Wesley (1994).

Kwee-Bo Sim, Kwang-Sub Byun,and Dong-Wook Lee, Design a fuzzy controller using schema coevolutionary algorithm, IEEE Transaction on Fuzzy Systems, 12, No. 4, 565-568 (2004).

Lo K. L. and Sadegh M.O., Systematic method for the design of a full-scale fuzzy PID controller for SVC to control power system stability, IEE Proc. Gener. Transm. Distrib, 150, No. 3, 297-304 (2003).

Mamdani, E. H., Application of fuzzy algorithms for simple dynamic plant, Proc. IEE, D-121, pp. 1558-1588 (1974).

Oysal Y., Becerikli Y., Ferit Konar A., Generalized modeling principles of a nonlinear system with a dynamic fuzzy network, Computer and Chemical Engineering, 27, 1657-1664 (2003).

Oysal Y., Becerikli Y., Ferit Konar A., Modified descend curvature based fixed form fuzzy optimal control of nonlinear dynamical systems, Computer and Chemical Engineering, 30, 878888 (2006).

Sharma S. K. and Irwin G. W., Fuzzy Coding of Genetic Algorithms, IEEE Transactions on Evolutionary Computation, 7, No. 4, 344-355 (2003).

Simant R. Upreti, A new robust technique for optimal control of chemical engineering processes, Computer and Chemical Engineering, 28, 1325-1336 (2004).

Soukkou A., Leulmi S., Khellaf A., How to Optimize the TS-Fuzzy Knowledge Base to Achieve a Desired Performances: Accuracy and Robustness, International Journal of Optimal Control Applications and Methods (OCAM), 29, No. 1, 19-40 (2008).

Takagi T., Sugeno M., Fuzzy identification of systems and its applications to modelling and control, IEEE Trans. Systems Man Cybernet., Vol. 15, No. 1, pp.116-132 (1985).

Tanaka K. and Sugeno M., Stability analysis and design of fuzzy control systems, Fuzzy Sets and Systems, 45, No. 2, 135-156 (1992).

Yonmook Park, Min-Jea Tahk, and Hyochoong Bang, Design and Analysis of Optimal Controller for Fuzzy Systems with Input Constraint, IEEE Transactions on Fuzzy Systems, 12, No. 6, 766779 (2004).

Zadeh L. A., Fuzzy Sets, Information and Control, 8, 338-353 (1965).

Zhang T., Guay M., Adaptive control of uncertain continuously stirred tank reactors with unknown actuator nonlinearities, ISA Transactions, 44, 5568 (2005).

Zhi-Hua Cui, Jian-Chao Zeng and Yu-Bin Xu, Dynamic Circle Nonlinear Genetic Algorithm, Proceeding of the Second International Conference on Machine Learning and Cybernetics, Xi'an, 2-5 November 2003, 18361840 (2003). 